\title{
Internal Auditory Canal
}

National Cancer Institute

\section{Source}

National Cancer Institute. Internal Auditory Canal. NCI Thesaurus. Code C95443.

A canal in the petrous region of the temporal bone that serves as the passage for cranial nerves (mainly the VII and VIII cranial nerves) towards the middle and inner ear. 